\title{
On organizing: an interview with James $G$. March
}

\author{
Jiyang Dong ${ }^{1}$, James G. March ${ }^{2}$ and Maciej Workiewicz ${ }^{3^{*}}$ (D)
}

\author{
* Correspondence: \\ workiewicz@essec.edu \\ ${ }^{3}$ ESSEC Business School, 3 Ave \\ Bernard Hirsch, 95000 Cergy, France \\ Full list of author information is \\ available at the end of the article
}

\begin{abstract}
In this interview with Professor James G. March, we focused on the key insights stemming from his work, with a special emphasis on the lessons for organization science and organization design. We discussed the major ideas and theories that he and his coauthors generated over the several decades as well as asked him about his views on the role of management research and business academia in general. The interview was conducted in September 2013 in Stanford, CA, and updated in August 2017 with a postscript from James G. March directed to the organization design community.
\end{abstract}

Keywords: Interview, Behavioral theory of the firm, Carnegie school, Organization design

\section{Introduction}

Jiyang Dong and Maciej Workiewicz

In the first issue of the Journal of Organization Design, Puranam (2012) summarized organization design as "getting multiple individuals with diverse knowledge and interests to collectively achieve something that they could not by acting individually." (Puranam 2012: 18). There are very few scholars who can confidently say that they have explored this challenge as comprehensively as James G. March has done. As one of the trio of the founding members (others being Richard Cyert and Herbert Simon) of what became known as the Carnegie School (Gavetti et al. 2007), James G. March wrote extensively about matters that are key to understanding how organizations make decisions, learn, adapt, and shape the collective efforts of their members. In this article, we present a transcript of the interview with Professor March conducted in 2013 in Stanford, CA and a postscript from him dated August 1, 2017, where he reflects on the future directions for organization design research.

James G. March, born in 1928, received his $\mathrm{PhD}$ in political science from Yale University in 1953 and served as faculty at Carnegie Tech (today Carnegie Mellon University), University of California, Irvine, and Stanford University. His research spans six decades over which he produced over 180 journal articles and books. March's scientific output transcends the disciplines in which he has held professorships-psychology, industrial administration, sociology, political science, education, and management. March coauthored two classic books: Organizations (with Herbert A. Simon in 1958) and A Behavioral Theory of the Firm (with Richard M. Cyert in 1963). The trio

(c) The Author(s). 2017 Open Access This article is distributed under the terms of the Creative Commons Attribution 4.0 International License (http://creativecommons.org/licenses/by/4.0/), which permits unrestricted use, distribution, and reproduction in any medium, provided you give appropriate credit to the original author(s) and the source, provide a link to the Creative Commons license, and indicate if changes were made. 
(Cyert, March, and Simon) created a novel theory of organizations that has been named the Carnegie School (Gavetti et al. 2007). It incorporated aspects of psychology, sociology, and economics to offer a new way of studying organizations that was vastly different from the theories of the time.

March wrote on many topics that are central to the science of organization design, like organizational goals (Cyert and March 1963; Cohen et al. 1972; March 1978, 1988, 1991b; Baier et al. 1986), organizational conflict (March and Simon 1958; Cyert et al. 1961; Cyert and March 1963; March and Olsen 1976), leadership (March 1984; Cohen and March 1974; March and Weil 2005), power (March 1956, 1957, 1966), organizational politics (March 1962; March and Olsen 1989), organizational decisionmaking (Cyert and March 1963; Cohen et al. 1972; March 1994), organizational rules and routines (Cyert and March 1963; March 1981; March et al. 2000), and organizational learning (Levitt and March 1988; March 1991a; Levinthal and March 1993; March 2010).

Echoing Puranam's (2012) recommendation, the future of the science of organization design may lay in returning to the roots and methods of the science on organizations initiated in 1950s by an ambitious group of scholars and their disciples concentrated around the peripheral Carnegie Tech, where James G. March played such an important role. With this interview, we hope to return to some of the more and less known ideas that came from under March's pen over the span of his distinguished academic career. We believe that these ideas are essential not only for understanding organizations but also for shaping them.

\section{The interview}

Interviewer:

Let's start with the first question. In your work, you present a world that is very challenging for human agents. It's a world quite distinct from the one presented in classical economics. Could you tell us a bit more about the key differences?

Prof. March:

First of all, you shouldn't over-emphasize the differences. At least in the early work, we really accepted the basic framework of classical economics. It was concerned with decision making and consequential decision making. People were looking at the world, trying to make decisions to put them at a better place in the world. The differences were fairly important, but the similarities were also there. Over time, the differences have grown, I think.

They come in two parts of the theory. One is the part about what kind of environment are organizations in. In the classical theory, the environment is knowable. That is, you can figure out what actions are connected to what consequences, at least up to a probability distribution. We tended to move toward a less knowable environment, one that was chaotic, it was complex, it was difficult to understand and tended to examine the effects of that kind of environment.

The other part that was different was the conception of the actors, whether they're individuals or organizations. In the classical theory, the actors had very good, consistent preferences. Their preferences were stable, they were consistent, they were precise and we found preferences to be somewhat unstable, generally inconsistent, and generally not very precise. That made a difference. The other thing was that we tended to 
observe that human beings had limited computational facilities. They could not deal with the complexity very well. The demands of a classical theory for the individual actors was very substantial. Those differences were fairly significant and over time, probably the most important difference that elaborated, in the early days but didn't emphasize, was the extent to which behavior is not driven by consequences, but is driven by some kind of routines or rules, and the logic is different.

Interviewer:

Taking into consideration that humans are boundedly rational, does organizing people reduce the effect of bounded rationality or does it introduce new challenges?

Prof. March:I think it's interesting that we call it bounded rationality because people emphasize the "bounded", but a lot of it was basically a rational view of decision making. Whether organizing increases or decreases the rationality is an open question. In some respects, it certainly increases rationality. It makes things more explicit, it makes - since people have to justify themselves to each other, and they tend to justify themselves in rational terms - it tends to move toward a rational ideology at least. On the other hand, when you have an organization, you have conflict, you have communication problems, you have an assortment of things of that sort that makes it probably harder to be perfectly rational.

Interviewer:

You mentioned conflict. When the actors in an organization are in conflict, what happens to the functioning of the organization? Does the organization stop acting or making decisions?

Prof. March:

Well, it doesn't stop acting, obviously. You may say that it's the concept of decisions that gets a little uncertain, but at least what we pointed out was that organizations sometimes attend to goals sequentially rather than simultaneously. There's this conflict, some groups get attended to today and other groups get attended to tomorrow and you hope that the joint effects will not be noticed. The organizations decentralize. They build buffers between the various preferences that they have so that one part of the organization is following one set of preferences and another part is following another set and the processes by which they're made consistent with each other are very weak. Yes, they do make decisions, they take actions, but those actions do not necessarily fulfill any notion for consistent rationality.

Interviewer:

Together with Michael Cohen and Johan Olsen (Cohen et al. 1972), you have introduced the garbage can model which caused quite a stir among the proponents of consequential decision making. Why was that so controversial?

Prof. March:

They should answer that, not I. I don't know why anyone would be concerned, but if I had to speculate, I think the title, "garbage can," probably offended peoples' sensibilities a little bit. If you're thinking seriously about an organization and trying hard to make decisions, for someone to say the process is like a garbage can is perhaps perceived as insulting. We thought it was playful, but it might be perceived as insulting. If you go beyond the label to the actual process, we found pretty often, people in organizations said that's what happens. It was not hard for them to see a garbage can process, but for some, it was too chaotic. There wasn't enough rationality to that system. 
Interviewer:

Originally the garbage can model was developed to describe an organized anarchy. Can this same model also be used to represent a competitive firm when there are more pressures coming from the environment?

Prof. March:

We first applied it to educational institutions. That seemed fairly straightforward. Subsequently, it seems it fairly easily applies to competitive firms. The kinds of things we noted, the connection of things by the simultaneity rather than by their substantive connection is as common in business firms as it is in educational institutions. Again, the ideologists of business firms would like to present them as highly rational. The realists of business firms recognize they really aren't. The garbage can contains many elements of proper description of what's going on there.

Interviewer:

You've written quite extensively on rule based behavior, calling it the "logic of appropriateness" (e.g. March 1991b). How is it different from the "logic of consequences" the type of decision making enshrined in classical economics?

Prof. March:

That's a very fundamental difference. We've spent a good deal of time talking about it. The simplest way of describing it is, if you follow a logic of consequences, what you ask is, "What are my alternatives? What are the consequences of each of those alternatives," and, "How do I value those consequences?" Then you act so as to achieve good consequences rather than bad consequences, or in the standard decision theory version, to choose the alternative with the highest expected value.

If you follow the logic of appropriateness, you ask a different set of questions. You say, "What kind of a person am I? What kind of a situation is this? I will do in this situation what a person such as I is supposed to do in this kind of situation." The logic of appropriateness does not ask what the consequences are. The logic of consequences does not ask what kind of a person am I.

Interviewer:

Can the two logics be reconciled?

Prof. March:

In some way, trivially. That is, if you are a true believer in the logic of consequences, then the logic of appropriateness is simply a solution by which you get the best consequences. The rules have evolved over time in such a way to be functionally best. Therefore, when you follow the logic of appropriateness, you are following the rules that have evolved in a consequential way. Therefore, you can predict the rules from the consequences. If you're a true believer in the logic of appropriateness, the consequential reason is simply one of those sets of rules. You have learned an appropriate thing to do is to calculate an expected value and choose the highest expected value. That's as rule bound as any other kind of rule and as empty of any kind of logic of consequence. It is simply an appropriate rule. You could easily do that, or some people do that, but it's not very productive to do that. I think these are better seen as two different logics, that most people have both of them in their repertoire, they use some sometimes and one sometimes and others other times. There's a tension between them sometimes, and that is closer to what actually is going on.

Interviewer: 
You started writing about the rule based behavior quite early; how has your conceptualization of rule based behavior evolved from the time of the Cyert and March (1963) book to now?

Prof. March:

It's hard for me to know. I think that in Cyert and March (1963), we basically said that a lot of behavior is routine. Organizations have standardized operating procedures and they follow standard operating procedures, that's a lot of the behavior. Nelson and Winter (1982) came along and said, "Those look like genes," and we can build an evolutionary theory around the idea that it is routine based behavior. I think, on the whole, that was a very interesting, good direction to go.

Later on, when Olsen and I started working (e.g., March 1984; March and Olsen 1989), we discovered that much of public sector organization is rule based and we became quite interested in how those rules are created, they change, how they're implemented, what kind of errors are made and things of that sort (March et al. 2000). We turn much more to what's the process by which rules evolve. That goes on in much of the stuff that I've done subsequently on learning, it is very much oriented to that.

Interviewer:

You mentioned the notion of routines from Nelson and Winter (1982), where the authors specified their own view of what those rules are, e.g., they are situated, context specific. Your notion of the logic of appropriateness seems to be similar with their conceptualization; but what, in your opinion, are the key differences, or similarities between those two concepts?

Prof. March:

I think they're fairly similar. There's very little in the Nelson and Winter discussions that I would disagree with. There's a little difference in emphasis, I think. I suspect the work that I've done and what the people working with me have done, is focused more on how do rules arise, how do they change, how are they implemented, what kinds of limitations are there and such things. It's much less functional as it does not try to say, "Do the better rules arise or do the poorer rules arise." If one just tries to see how rules arise, how are they used. Nelson and Winter's rules are embedded in an evolutionary framework, and although their evolutionary framework is not the evolutionary framework of simple equilibrium and the reliable outcomes, they are still pushing more and more toward how the system as a whole evolves over time.

Interviewer:

You wrote that the logic of appropriateness may leave individuals to follow rules without, or in spite of, the calculation of consequences and expected utilities. It's quite surprising to expect a person to make a decision that intentionally chooses the inferior alternative, isn't it?

Prof. March:

It's only surprising if you believe in the logic of consequences. It's surprising if you think people ought to prefer alternatives that lead them to better consequences. But it's not surprising at all if you think, "That's not how it happens." You say what kind of a person am I? What does such a person do? We know all kinds of examples where people pursue what they think is appropriate to their identity that lead them to bad consequences and the consequences may or may not matter to them, but the procedure does not start from, "What are the consequences?" Much of our behavior currently is of that form. 
I am a man, I do what a man does. Most men doing what a man does get into trouble from time to time. Or, I am a plumber. I do what a plumber does. Plumbers sometimes get into trouble doing what a plumber does.

Interviewer:

How is the logic of appropriateness connected to things like moral behavior, ethics, or culture?

Prof. March:

As you well know, there are quite a few theories of ethics. One of those theories of ethics is basically rationality. It is ethical as long as it is rational, that's basically the idea. Most theories of ethics are not quite that form. Most theories of ethics imagine some set of rules, or some set of procedures, that may in fact get you to a place that's different from consequential analysis. The virtue that is celebrated in morality is that virtue of doing what you're supposed to do, not what is good for you economically or consequentially.

Most theories of morality contrast consequentiality with some kind of moral code. In the Christian religion, the Ten Commandments do not say, "Thou shalt not commit murder unless it works well for you." That's not what they say. They say, "Thou shalt not commit murder." Most of the moral codes have that character to them. They indeed, most of them, have the proposition that there's no virtue without temptation. Temptation, in the moral code, is almost always consequential. It's something, some way in which you can be better off if you violate the code. Unless there's that, the code isn't very important. I think it was Kierkegaard who said, "If a religion can be justified," and he meant justified consequentially, "it is hardly a religion." The only justification of religion is that it demands things that are not consequential. I think a lot of moral codes are of that sort.

Interviewer:

A rule based behavior conjures up images of an automatic, stable and reliable process. To what extent is it so?

Prof. March:

You have to have a mixed answer to that. It's clear that rules change, that they aren't reliably enforced or followed, that they may be quite inconsistent, one rule might be quite inconsistent. All those things we observe. At the same time, we should notice that making rules, making routines, are a fundamental instrument by which organizations achieve stability and reliability. That's their purpose quite often, the purpose is achieved quite often. You want a rule often, in order to get stability and consistency and reliability. As you well know, they don't always produce that. One of the things interesting to study, when you study rules, is how they change, how people deal with multiple conflicting rules, and how people avoid following them.

Interviewer:

Can you tell us a little bit more about the process through which rules can change?

Prof. March:

I co-authored a book on that which I'm sure you've read. We tried to study the rules at Stanford University and understand, in a very quantitative way, what are the factors that produce changes (March et al. 2000). I'm not sure I can reproduce right now all of the results, but we asked questions like, "Is the change more likely if it is done more often? If a rule has changed more often in the past, is it more or less likely to change 
now? If a rule has changed recently, is it more or less likely to change now?" I think we found, in general, that the more often a rule has changed, the more likely it will change again. The more recently it changed, the less likely it was to change again. Those results are specific organizations and a specific set of rules, but it's the kind of question you might want to ask. You also might want to ask, [although] it's a little harder to ask quantitatively "What are the political conditions for rule change?" One of the things we observed was that rules changed when there were problems. Problems in an organization are often political. You get relatively large numbers of changes under conditions in which there are problems and then those changes and the rules have a certain dynamic of their own, subsequently.

Interviewer:

We know that rules are coded from experience. It's normally assumed that more experience would lead to more intelligent behavior, better rules that lead to superior performance.

Prof. March:

That's the fantasy of some evolutionary theories. There are problems with it, of course. First of all, what is intelligent behavior? Most people, I think, mean by intelligent behavior, behavior that satisfies your preferences, or something like that. That gets a little difficult if your preferences are changing and are in conflict and so on. If you observe, as we did in that book (March et al. 2000), that rules solve problems, then in the sense that the problems faced get smaller, then, yes, rules reduce the problems' face and that's consistent with the proposition that over time, rules have fewer and fewer changes because they're eating into the problems' face, they're no longer problems. In that sense, they're more intelligent. The notion that magically, through learning, we will end up with an optimum set of rules, I think is fanciful. The process has all the traps of standard evolutionary theory. There aren't typically equilibria, and if there are equilibria, there are multiple equilibria. In some sense, I think it's likely that most of the time, as rules change, they in some sense, make things better. Whether they're more intelligent in some long-run sense is harder to claim.

Interviewer:

Can you tell us a little bit more about those traps - the standard evolutionary traps when it comes to learning from experience?

Prof. March:

My favorite one, of course, is the competency trap (Levinthal and March 1993). Your performance on a particular activity is a joint effect of the activity's potential and your skill at the activity. As you gain experience, your skill gets greater, so you do better with that activity. That complicates making choices among activities because you're more skillful at some than at others, and the joint effect is that you end up preferring to do something that is not the best, optimal activity. That is, more or less, an excellent thing. When you choose an activity and are successful at it, you will use it again. When you use it again, you get better at it. When you're more likely to be successful, it's a very nice, tight, positive feedback move. I think it's one of the more important observations we have in our studies of organizations.

Interviewer:

From time to time, also an organization might encounter the situation that they don't have enough experience to make a decision. How do they overcome the problem of paucity of experience? 


\section{Prof. March:}

The question is quite right. That is, normal experience is quite limited. You're trying to make judgments on the basis of single cases or a small number of cases. In a world that is quite complex and probabilistic, what happens in a single case or a small number of cases may be quite distant from what the average performance is. How can you combat that? One obvious one, which many people have noticed, is to be relatively persistent in a sense that says, "Don't learn too fast. Don't adjust too quickly on the basis of small amounts of data." Now, there's some cost to that, of course. The errors of fast learning are pretty obvious. The more traditional ways are to do small experiments. If you do small experiments, you can run them for a fair amount of time, you can see what works, what doesn't work, and assuming you can scale up without any difficulty, then you can take the better results from the small experiments and make large commitments. Very sensible activity.

Another one is to steal from your competitors. Let them run the experiments, and you learn from them. Insofar as you can, that's a perfectly good way of experimenting at low cost. I think the big secret in this is to recognize that normal learning, under samples failure, normal learning makes you abandon things in which you fail before you know much about them. Therefore, you are likely to abandon good things too soon. Of course, if you're persistent and you stay with bad things, quite often you will just be pouring more money down the drain. That's a standard problem of learning.

Interviewer:

You wrote that engineering organizations is quite a formidable task. Is it possible to improve on the evolutionary process?

Prof. March:

Sure. If you understand it, then that's when you understand that you can almost always see ways in which you can intervene. In most evolutionary processes, there are two kinds of things you can "improve" on. One is to improve the efficiency of the selection. The other is to improve the variety of the novelty in the process. If you look at organizational evolution of rules and so on, the efficiency is really how you improve learning, and as I mentioned earlier, one of the things that is usually possible with learning is to increase the persistence with failure.

The other aspect of efficiency is imitation. The imitation of others. One of the dangers of imitation is that everyone is connected to everyone else they imitate, and they converge too fast to a sub-optimal solution. One of the things, and the engineering trick, is to keep people somewhat disconnected so that they do not converge too rapidly. I've claimed at least that's one of the advantages of traditional nationalism. The great advantage of a separation between European scholars of organization and North American scholars of organization is that they did not converge. Similarly, Asian scholars. There's some cost to that, but it's very important for improving the efficiency of imitation.

The other side is the novelty. How do you encourage novelty? I've worked an awful lot on that. I don't know that I have a good understanding of it, but I understand some of the problems. The deepest problem with novelty is that most novel ideas are bad ones. If you specialize in novel ideas, you specialize in bad ideas, and that's not a good way to survive. Somehow or other, in a system, you have to encourage more novelty without killing off everybody. That's an engineering problem where the sort of Silicon 
Valley type solution is to have easy entry, easy creation and quick death so that, I don't know what the percentage is, but something like $90-99 \%$ of Silicon Valley start-ups die.

All of them, or many of them, are trying novel things and so there's a lot of novelty and most of it does not affect the major companies because they're not doing it. That's one sort of classic solution. Have novelty focusing new entries that are small and you can kill off very easily. Suppose you want to have novelty in your own organization. Then, one obvious strategy is to decentralize to create a little startup within your company with all the properties of a startup. Some companies have tried that with some success. If you look at things like what made Xerox PARC so innovative. It's hard not to look at that history without saying one of the things that made Xerox PARC so innovative is that it was really disconnected from the company. No one was paying any attention to what they were doing. No one was profiting from anything they were doing. They were doing whatever they damn pleased, and that seemed to help the creation of novelty.

I've done a little work on trying to understand what I call the "generation of outliers," and looking at the RAND Corporation (Augier et al. 2015). For a brief period in the 50s and 60s, the RAND Corporation generated an awful lot of new ideas, particularly in economics and organizations. It's a very similar story. The key thing in that case is that they were cut off from the Air Force. In this case, they were cut off, but they were enthusiastically supported. That's a good combination. If you're going to engineer an evolutionary process, you have to work on improving selection, and you have to work on improving novelty.

Interviewer:

Your depiction of this Silicon Valley model seems to be closely related to the technology of foolishness. Who is the fool and who benefits from the foolishness in this case?

Prof. March:

The idea of technology of foolishness, was you needed somehow to generate ideas that were new, a novelty. They would, in fact, look foolish to the establishment, to the established ideas. What makes a fool and what makes a fool persist? I think that there are probably lots of answers to that, but let me point out one. The fools tend to be disconnected from the establishment. The sort of standard stories in Silicon Valley is that if you go drop out of college, or they don't feel comfortable in college, the fools tend to congregate with each other. You have collections of fools, called hackers, or whatever they're called. For me, it sounds an awful lot like juvenile delinquents. I think if you want to understand generating novelty, look at juvenile delinquents. Here are a bunch of people who do a lot of novel things. Most of them are socially unacceptable, but they are novel and they know that they're rejected, they suffer for it, but they form gangs and those gangs support them, and they persist.

Novelty is usually called an alien intruder that organizations and societies will react to aliens and intruders in a negative way. How do you protect alien intruders from elimination? I emphasize that because the romantic stories of novelty and creativity and foolishness make it sound as though it's a glorious thing and the victors won and everyone gathered around and cheered them. That's the final stage of a long process of being kicked and scorned and everything else.

Interviewer:

Xerox PARC is a wonderful example of a technological novelty, but also a prime example of a missed business opportunity. How can organizations harness this novelty, how can they be not only supportive, but also inviting of this novelty without suffering the consequences? 
Prof. March:

I think it's very difficult. Socially, I'm not sure it's a good idea. The key to Xerox PARC was that Xerox didn't pay any attention to them, didn't use them. If Xerox had paid more attention, Xerox PARC probably would have developed in a different way, in a less creative and interesting way. You want, in your whole system, you want some of these deviant, alien cultures to survive, but to integrate them into an individual company will tend to undermine them. Then your engineering problem is fairly severe. How do you get Xerox to create an organization that doesn't really help Xerox in its competitive thing, but helps the industry? That's a very fundamental, a fairly general problem in the novelty area that you need novelty, but novelty is unlikely to help, particularly the places where it is born or nurtured. That's a standard problem in organizations, in societies of organizations. There are some things that are good for society, but not particularly good for the organization. We have difficulty with that.

Interviewer:

How can society support and maintain foolishness?

Prof. March:

I think it does it mostly by mistake. We all know that organizations generate slack. Slack is a breeding ground for innovation, it's also a breeding ground for laziness and a lot of other things. It relaxes control, and when it relaxes control, it allows novelty to arise and some small fraction of that novelty may be useful. You have to have a kind of system that is willing to go with a process that generates mostly mistakes, and an occasional good thing. That's a hard system to create.

Interviewer:

You wrote about beauty, truth and justice as important criteria in evaluating social science theories. How do you think classical economics and behavioral theories in the Carnegie tradition should score in each of these dimensions?

Prof. March:

I think that's a good question, but I'm not sure I can give it a very precise answer. I think that, on the criterion of truth, behavioral theory clearly wins. There is question, because some of my friends would disagree, but I think it's fairly clear that the behavioral theory comes closer to accurately describing what goes on in organizations. With respect to beauty, I think it's fairly clear that economic theory is more beautiful. It's simpler, it's more elegant, you can actually derive theorems and all this wonderful stuff. With respect to justice, I would say that the behavioral theory clearly has an advantage. Economic theory generates people who are greedy and unconcerned about social welfare. That's a natural consequence of the thinking and the way I've talked about justice of a set of ideas is, "Do they create people who make the world better?" In this case, I would say that economic theory creates people who make the world worse.

Interviewer:

The question of power was something that you felt very strong about, but didn't write much about. Why?

Prof. March:

I think I'm in print to say that emphasis upon power tends to produce people who are less attractive than theories that don't emphasis power. By and large, I've written about power, but I don't use it as a construct very much.

Interviewer: 
If the worlds that the organizations occupy is too complex to understand, let alone to control, then what is the role of leaders in this world?

Prof. March:

The simple answer is that we are humans and we need to tell stories. We need to tell stories that glorify the human estate. We need heroes. We need to imagine that human actions made a difference. Leaders are part of the classic story by which we come to imagine that. We tell stories about leaders and leaders tell stories about themselves that allow us to imagine that we control an uncontrollable world. That's very good. I think, if you could just imagine - suppose you had a choice, a world that's uncontrollable would you rather imagine that you could control it, or give up? For me, the human being who imagines he or she can control it is a more attractive human being.

It's possible to construct an ideology, and I've occasionally tried to, in which you combine the notion of the world as not controllable with the notion that you're still going to act decisively. I attribute that to people like Don Quixote, but even more people to Chinese philosophy. The thread that runs through Chinese philosophy that fascinates me is the thread that says the leader should be decisive, but skeptical. They should act firmly, but not be very sure that he's acting correctly. Westerners have great difficulty doing both of those. I used to call it optimism without hope (March 1999). You strike ahead forward, even though in the back of your head, you say, "I don't have the vaguest idea if this is going to make any difference." If you can do that, if you can combine those two, I think you're closer to being able to survive well. Most of our training is that in order to have great action, you have to have great hopes. A lot of reasons I'm somewhat enthusiastic about that Chinese tradition is that it allows you to have great action without having great hope. "I'm going to charge, probably won't make any difference, but that's what I'm going to do."

Interviewer:

Related to this is another question in a similar spirit. When we're observing proponents of organizations, and sometimes they have huge success sometimes fiasco, how can we attribute such outcomes to organizations' true capability or to just luck?

Prof. March:

As you well know, most of the results that we observe probably can be attributed to luck. It's very hard to reject the notion that it could be luck. The one in ten million people who have heroic, great results, that's about what you'd expect if you had ten million people trying, and so on. It's fairly hard to reject the notion that it's all luck. This is a stochastic world and stochastic worlds produce all kinds of interesting results for which we like to give more causal explanations. I used to say that the most important book in modern social science, post-World War II social science, was Feller's book, An Introduction to Probability Theory and Its Applications ( 1957) because he laid out all of the ways in which stochastic processes generate results that you would certainly think must have been attributed to something else. That's a theme that Jerker Denrell and Christina Fang (2010) have picked up on recently. Of course, that doesn't quite settle it. You can say, "Yes, all the things we observe are consistent with the notion that this is just a vast probabilistic generating machine."

They're also consistent with the possibility that there's actually some skill involved. It's very unlikely that we'll have the data that will allow us to discriminate. To discriminate between those two normally requires some kind of experimental setting. It's quite 
possible that there's an experiment that we've got somebody who knows how to experiment. The complication for evolutionary theory, in reality, is we have breeders who keep intervening and producing new species or changing species. They do that intentionally, deliberately, and they change the world. We sometimes do it unintentionally, the nice evolutionary theory really works better without people who are screwing it up by breeding. The same thing is probably true in the world of management.

Interviewer:

Business schools use case studies a lot, but how much can one learn from them?

Prof. March:

I'm not an expert on business cases, so I've never used one in class. If they're done carefully, done well, they're data. They're like any other kind of field case study. Field case studies themselves are difficult to make very useful because it's hard to know what this one case really tells you. You can learn something, and there are ways of doing that. At least without studying them closely, it seems to me one of the risks of business cases is that they're written, often, for teaching purposes. That means that the instructor is trying to get across some point. If you're trying to get across some point, you should not be doing field research.

In field research, you have to be listening to the field, the data, not imposing your ideas on the data, and making an interpretation. Of course, business case researchers always are struggling with the trade-off between access and credibility. They want to get access to this company, and the price of getting access is to lie about the company, or to make your presentation acceptable to the company. That, in the business cases that are embedded in business school training have that problem very severely. Every once in a while they get caught. In the Enron cases, I think have been withdrawn because they didn't really portray Enron as it really was. I suspect that's generally true.

Interviewer:

Managing organizations is already so hard, so how about studying them? What are the main challenges in doing research on organizations?

Prof. March:

I used to say to my students that unfortunately, God gave all the easy problems to the physicists. It is difficult. It's a world that is complex that is shifting all the time. It is hard to get access to it to study, it's hard to do experimental studies. There is not an easy way. I don't think that's a reason for giving up. I think it's a reason for charging ahead, but being skeptical. I think we need tougher minded people than you need necessarily in physics and chemistry. They have to be very tough about all the ways in which they can be misled by the data. They have to be committed to finding knowledge and most of my colleagues seem to be more committed to getting a publication than finding knowledge, that's unfortunate. It's hard.

Unfortunately, you recruit smarter people to easy problems than you do to hard problems. Smart people like to be in domains where they can be demonstrably smart. You go to mathematics or physics and you can demonstrate your smartness. You go to sociology or psychology, it's harder. A lot of the observations of your skills are subject to random fluctuation. Even though you're smart, you may be viewed not as smart. A smart person prefers to go places where they're actually viewed as smart. On the whole, we have a field that tends to recruit people who are not quite as smart as some other fields. They overlap, the distributions overlap, but the mean is lower. We have to live with that. 
Interviewer:

To be pessimistic without despair.

Prof. March:

Pessimistic, but committed. Charge, but be skeptical.

Interviewer:

Should our scholars strive to be managerially relevant?

Prof. March:

I've written a bit about that (Augier and March 2007, 2011). Mostly, what I've written is that the pursuit of relevance is the enemy of the pursuit of knowledge. I don't believe that absolutely. I think the pursuit of relevance actually has some advantages. It gives you focus, it gives you a sense of progress and a lot of other things like that. In our field, the pursuit of relevance leads you to abandon, too fast, the pursuit of knowledge and to become a kind of second rate consultant. Most of that is tied to the extent to which our studies are keyed to finding out what makes a difference in organizational performance. It's a topic that is almost certainly not going to yield results as we know enough already to know that untangling what makes results positive results or negative results, is very hard to determine from a case study or even a relatively numerous study. Yet the pressure to do that is so strong, that a very common dependent variable is performance.

We know that performance is not very good as a dependent variable (March 1999). It's very good as an independent variable. Performance affects a lot of things and we can measure those. Every time we try to say what makes performance, we don't do very well. Most of the relevance sort of ties into that. I used to say to my students, when they asked me the relevance of some idea that I was presenting, "That's your problem, not my problem." That's the problem with the person in the field, on the line, trying to figure out what to do. How can you use an idea in this situation? That's something that he can do, but for the person trying to work on ideas, that's not a very good activity.

Interviewer:

Over the years, you have mentored an impressive group of Ph.D. students who later became prominent scholars. What qualities characterized good students, and how can they be nurtured?

Prof. March:

What makes good students? It happens long before they get to graduate school. You only take advantage of them, you don't create them. I think that it's not terribly complex. It is people who are smart, independent, and committed to knowledge, committed to finding knowledge. That eliminates a lot of people. Some good people are just not smart enough. Some people are not independent enough and some are not committed enough to knowledge. I encounter a fair number of smart students these days, who are mostly committed to getting a publication in an A-Journal. That seems to me a very weird kind of definition of one's objectives in life, but it's a fairly common one.

I have a great nephew, very smart young man, who breezed through college and then he thought about where he wanted to go to business school, and he ended up going to Wharton. He ended up as any good, smart person going to Wharton would, in the finance industry. He ended up in Brazil making tons of money. He is now awakened to the fact that he really didn't learn very much. He learned a lot about this sort of stuff, but he doesn't know much about the fundamentals of life and he's now in the business 
of hiring people. He says he doesn't want to hire these people from Harvard or Wharton. They're just like he was; they don't have any interest in the knowledge and to me, he was sweet enough to say the Stanford students have an interest in knowledge, so we want to hire Stanford. I'm not sure how much of that was flattery and how much was real, but I think the point is right, particularly if you're talking about research, you want someone who's driven by a desire for knowledge.

I had the great good fortune, I got my Ph.D. at Yale University in the Department of Political Science. When I went there, the Department of Political Science was torn with very tough conflicts among the faculty, they hated each other. As a result, they had very little time to interfere with my education, and I got a very good education, but the faculty had almost nothing to do with it. It was a great library, and great colleagues and so on. I think that's true in general, the faculty may have some marginal impact, but what it really is, you want a faculty that doesn't interfere with you as you go on learning.

I think the students for whom I take credit, all had that attitude. They all had some notion they were going to do something. They were not particularly interested in what I wanted them to do, but they would talk to me. You have to drink wine with someone for four years before you can talk seriously about anything. To talk seriously, you have to put yourself on the line and you have to really care and so on. Most of them drank wine with me for four years or something like that, and that seems to me, is the optimal educational procedure.

Interviewer:

In terms of teaching, you have talked about scholars. What should we be teaching the future business leaders? Where do you think that current business curriculum is lacking?

Prof. March:

Well, I'm an academic. I think universities - people learn from lots of different places - but universities have a special role. Universities should be teaching the fundamentals. If you're talking about business people, they often need to know something about accounting, something about loans, a lot of relatively routine learnable things that they can probably learn from a good computer problem. What the universities should offer is training in the fundamentals. It is more important for them to learn game theory than it is for them to learn the difference between first in or last out or whatever the hell it is in accounting.

An optional business school would probably look like an advanced liberal arts college. That is, you should learn some fundamental economics, you should learn some fundamental philosophy, you should learn some fundamental history and there should be a fairly high level of intellectuality, but it shouldn't worry very much about things like business cases because that can be learned on the job. Maybe you have to teach people vocabulary so they can speak a certain vocabulary, but that shouldn't take very much time.

Interviewer:

In your own research, you have drawn very richly from different fields. Many of your papers are great examples of interdisciplinary work. What do you see as the main challenges in this approach?

Prof. March:

I think it's a big problem. It's a problem on several scores. We have a lot of enthusiasm at Stanford for interdisciplinary centers. The problem within interdisciplinary work 
is that it's hard. In order to do interdisciplinary work, you have to be a fully qualified person in both or all three or all four disciplines, and that's not very easy for most people. As a result, the people who go into interdisciplinary work are underqualified for the work. The work gets a bad name, and so it's even harder to recruit good people into it. The best people go into the core of the disciplines and it's hard to entice them out into interdisciplinary things. You can do that, but you can't do it by hanging up a sign saying, "this is a center for interdisciplinary research." You'll get some interesting people, some very good people, but most of the best people will not show up.

If you're going to be a biochemist, you have to know chemistry and you have to know biology, and you have to be able publish in the journals in both fields and to be accepted as respectable in those fields, and if you're going to be a psychosociologist, whatever that may be, you'd better know psychology, know sociology, and be able to publish in the good journals in both and so on. That's hard for most people and so you get a pool of scholars that is not as strong as you wish.

Interviewer:

It seems like the behavioral theory of organizations, what you once called the "Heresy in the Church of Rational Dogmata," became quite successful, at least judging by the number of citations that the books and subsequent papers got. Do you think that the struggle for dominance is over?

Prof. March:

There is a paper that I'm not sure you found. It's called, "The War is Over and the Victors Have Lost" (March 1992). That paper is a tongue-in-cheek paper, so you're never quite sure when I'm serious, when I'm not in that paper. The argument, at least, is that what's happened is that the sacred church has kept the sacred dogma, but has changed the actual content of the dogma very significantly in the direction of behavioral ideas. It is still understood that everyone maximizes expected value and seeks the optimum. By the time you get all the qualifications of all the specialties around it, it sounds an awful lot like the behavioral theory of the firm. I think there's some truth in that, but not the entire truth.

If you look at the recent Handbook of Organizational Economics edited by Bob Gibbons and John Roberts (Gibbons and Roberts 2013), I think, it's all pretty much economics. There's very little behavioral stuff in there. There's transaction cost economics which sort of is a derivative, but the citation, I counted the Cyert and March (1963) citations in the index and I now, at the moment, don't remember the number, but it was something like 6. If you count the Holmstrom (Hölmstrom 1979) citations, the numbers will be 80 -something and so on. There are a number of people who will have 75-100 citations, they're all economists. I took some solace in the fact that Cyert and March (1963) was cited more often than Adam Smith (1776), but if you read the Handbook of Organizational Economics (Gibbons and Roberts 2013), you'd say this is pretty much economics and there's some minor bows to other things. I don't think the war is over, really. I think that there a lot of good economists who worry about the future of economics, whether you can really build everything on classical economics. I'm not sure that they have any agreement on what to do.

Interviewer:

If the struggle is not over yet, what do you see as the -.

Prof. March: 
It's a struggle. I don't know. I think you should do your own work and let the world decide who is winning the war. I've probably spent more time than I should harassing economists. Time is better spent doing your own work, getting your own ideas out and not trying to decide whose ideas should be sacrificed.

Interviewer:

What do you consider as the next promising avenues in the organizational theory field?

Prof. March:

I don't know. What are the promising avenues of the past? If you look at the promising avenues of the past, I think you would have to say something like the behavioral theory of the firm is one of them. You'd say that network theory is one of them. You would probably say that population ecology is one of them. You'd probably say that the game theory and the organizational economics is one of them. Did anyone predict that those would be the next? Yes, probably somebody did, but I don't know it.

In the domains in which I work, there's a lot of work yet to be done on the sort of evolutionary learning aspects of organizations. We've really made some initial steps that are pretty good, but there's still a lot of work, and a lot of empirical work that needs to be done. We're a little long on theoretical statements, a little short on empirical stuff. That happens to be the domain I work in, so that's where I think the future is and my experience in the past is the future sort of pops up from left field somewhere and the next thing I know, there's this very interesting study that has nothing to do with anything I do.

If I really were going to answer that question, I would also say, where are the interesting new ideas in chemistry, physics, biology, whatever, because we steal a lot. I think, for example, we've stolen evolutionary theory. In fact, the evolutionary theory of people like Nelson and Winter is in many ways a better biological evolutionary theory than the conventional biological theory because the conventional biological theory has had some trouble with the same issue that we've had in economics, a tendency to want to imagine a perfectly efficient, functional, operating system called evolution. It's only as they've gotten into it that they come to see that it's not quite so perfectly efficient.

The other thing that I tell my friends a good deal, particularly talking about novelty, which is a direction we might go, is that until we get something analogous to Mendel (1866), something analogous to understanding the combinatorics of novelty, we'll just talk about combinatorics but we won't really get a grip on them. That's a huge task. You have to figure out what the elementary units are, you figure out what the combinations are, figure out how they get combined, and it's possible it will never go that way. That's the sort of thing that would be a great thing for you guys to do.

Interviewer:

At least we can build on your work on the technology of foolishness.

Prof. March:

There you go. The Technology of Foolishness was published in 1970 or ' 71 or something around there. I think it's time for improvement. Make some improvements.

\section{Conclusion}

Postscript by James G. March, Stanford University, August 1, 2017

Buried in the twentieth century history of writings about organizations are some prolific contributors who worried about the design of organizations. The distinguished 
names include Gulick and Urwick (1937), Mooney and Reiley (1939), Urwick (1943), Fayol (1949), and Devons (1950). The burial was celebrated most conspicuously in Chapter 2 of March's and Simon's magisterial treatise Organizations (1958) where five limitations of classical administrative science were listed:

"(1) The motivational assumptions underlying the theories are incomplete and consequently inaccurate. (2) There is little appreciation of the role of intraorganizational conflict of interests in defining limits of organizational behavior.

(3) The constraints placed on the human being by his limitations as a complex information-processing system are given little consideration. (4) Little attention is given to the role of cognition in task identification and classification as well as in decision. (5) The phenomenon of program elaboration receives little attention.” (p. 33)

Efforts to remove these limitations have filled many pages of research reports subsequently, and I think it is reasonable to declare progress in these respects.

However, the baby went out with the wash. The concern with improving the design of organizations that animated early writers on administration was relegated to folklore. Is it possible to imagine resurrecting their interests without repeating their errors? Yes, I think so. In particular, it seems to me that there are at least three thrusts of recent work that warrant some serious thought in contemplating organization design. The first is the recognition of identities and logics of appropriateness as major drivers of human behavior in organizations. The second is the realization that imitation (diffusion) through networks of connections is a primary driver of organizational adaptation. The third is the importance of learning in human organizations as an instrument of change and resistance to change and the profound limitations to the effectiveness of experiential organizational learning.

Beyond that, I think students of organizations need to explore the implications of contemporary efforts to take the humans out of human organizations. Insofar as robots perform the physical tasks of organization and artificial intelligence performs the management tasks, organizations will still exist and their design will still be critical; but the issues and their resolution will be somewhat different.

When I was a student, the principal instruments available to extend human intelligence were the printing press and the slide rule. Both replaced earlier forms of memory and calculation and made major leaps in human capabilities possible. The computer and the software implementations of its capabilities have produced and portend major additional changes. One does not have to wander too far into science fiction to imagine a confrontation between these instruments of intellectual ambition, on the one hand, and core human values and routines of life as they have developed over 3000 years, on the other. Organizations are likely to be major arenas for that confrontation and major factors in its outcomes.

Acknowledgements

Many thanks to Gabriel Szulanski for the encouragement and support throughout the project.

Funding

We would like to thank INSEAD's Doctoral Program fund for the generous support during the development of the interview. 
Authors' contributions

JD and MW were the interviewers and contributed to the introduction. JGM was the interviewee and contributed to the postscript. All authors read and approved the final manuscript.

Ethics approval and consent to participate

Not applicable

\section{Consent for publication}

Not applicable

Competing interests

All authors declare that they have no competing interests.

\section{Publisher's Note}

Springer Nature remains neutral with regard to jurisdictional claims in published maps and institutional affiliations.

\section{Author details}

${ }^{1}$ Hong Kong Polytechnic University, Hung Hom, Kowloon, Hong Kong. ${ }^{2}$ Stanford Graduate School of Business, 655 Knight Way, Stanford, CA 94305-7298, USA. ${ }^{3}$ ESSEC Business School, 3 Ave Bernard Hirsch, 95000 Cergy, France.

\section{Received: 10 October 2017 Accepted: 15 November 2017}

Published online: 06 December 2017

\section{References}

Augier M, March JG (2007) The pursuit of relevance in management education. Calif Manag Rev 49(3):129-146

Augier M, March JG (2011) The roots, rituals, and rhetorics of change: North American business schools after the Second World War. Stanford Business Books, Stanford

Augier M, March JG, Marshall AW (2015) The flaring of intellectual outliers: an organizational interpretation of the generation of novelty in the RAND Corporation. Organ Sci 26(4):1140-1161

Baier VE, March JG, Saetren H (1986) Implementation and ambiguity. Scandinavian Journal of Management Studies 2(3):197-212

Cohen MD, March JG (1974) Leadership and ambiguity: the American college president. McGraw-Hill, New York, NY

Cohen MD, March JG, Olsen JP (1972) A garbage can model of organizational choice. Adm Sci Q 17:1-25

Cyert RM, March JG (1963) A behavioral theory of the firm. Prentice-Hall, Englewood Cliffs, NJ

Cyert RM, March JG, Starbuck WH (1961) Two experiments on bias and conflict in organizational estimation. Manag Sci 7(3):254-264

Denrell J, Fang C (2010) Predicting the next big thing: success as a signal of poor judgment. Manag Sci 56(10): 1653-1667

Devons E (1950) Planning in practice. Cambridge University Press, UK

Fayol H (1949) General and industrial administration, Pitman, London

Feller (1957) An introduction to probability theory and its applications. Wiley Inc., New York

Gavetti G, Levinthal D, Ocasio W (2007) Neo-Carnegie: the Carnegie School's past, present, and reconstructing for the future. Organ Sci 18(3):523-536

Gibbons R, Roberts J (2013) The handbook of organizational economics. Princeton University Press, Princeton Gulick L, Urwick L (1937) Papers on the science of administration. Institute of Public Administration, New York, NY Hölmstrom B (1979) Moral hazard and observability. Bell J Econ 10(1):74-91

Levinthal DA, March JG (1993) The myopia of learning. Strateg Manag J 14(S2):95-112

Levitt B, March JG (1988) Organizational learning. Annu Rev Sociol 14:319-340

March JG (1956) Influence measurement in experimental and semi-experimental groups. Sociometry 19(4):260-271

March JG (1957) Measurement concepts in the theory of influence. The Journal of Politics 19(2):202-226

March JG (1962) The business firm as a political coalition. The Journal of politics 24(4):662-678

March JG (1966) The power of power. Easton, David, ed. Varieties of Political Theory. Prentice Hall, New York, NY

March JG (1978) Bounded rationality, ambiguity, and the engineering of choice. Bell J Econ 9(2):587-608

March JG (1981) Decisions in organizations and theories of choice. In: Van de Ven AH, Joyce WF (eds) Perspectives on organization design and behavior. Wiley, New York, NY, pp 205-244

March JG (1984) How we talk and how we act: administrative theory and administrative life. In: Sergiovanni TJ, Corbally JE (eds) Leadership and organizational culture: new perspectives on administrative theory and practice. University of Illinois Press, Urbana and Chicago, pp 18-35

March JG (1988) Decisions and organizations. Blackwell, UK

March JG (1991a) Exploration and exploitation in organizational learning. Organ Sci 2(1):71-87

March JG (1991b) How decisions happen in organizations. Human-Computer Interaction 6(2):95-117

March JG (1992) The war is over and the victors have lost. J Socio-Econ 21(3):261-267

March JG (1994) Primer on decision making: how decisions happen. Simon and Schuster, New York, NY

March JG (1999) The pursuit of organizational intelligence: decisions and learning in organizations. Blackwell Publishers, Inc., Cambridge, MA

March JG (2010) The ambiguities of experience. Cornell University Press, Ithaca, NY and London, UK

March JG, Olsen JP (1976) Ambiguity and choice in organizations. Universitetsforlaget, Norway

March JG, Olsen JP (1989) Rediscovering institutions: the organizational basis of politics. The Free Press, New York, NY March JG, Schulz M, Zhou X (2000) The dynamics of rules: change in written organizational codes. Stanford University Press, Stanford, CA 
March JG, Simon HA (1958) Organizations. Wiley, New York, NY

March JG, Weil T (2005) On leadership. Blackwell Publishing, Malden, MA (first published in French in 2003 as Le leadership dans les organizations)

Mendel G (1866) Versuche über PIflanzenhybriden. In: Verhandlungen des naturforschenden Vereines in Brünn, Bd. IV für das Jahr 1865. Abhandlungen, pp 3-47

Mooney AC, Reiley JD (1939) The principles of organization. Harper, New York

Nelson RR, Winter SG (1982) An evolutionary theory of economic change. Belknap Press, Cambridge, MA

Puranam P (2012) A future for the science of organization design. Journal of Organization Design 1(1):18-19

Smith A (1776) An inquiry into the nature and causes of the wealth of nations. W. Strahan and T. Cadell, London

Urwick L (1943) The elements of administration. Harper, New York

Submit your manuscript to a SpringerOpen ${ }^{\circ}$ journal and benefit from:

- Convenient online submission

- Rigorous peer review

- Open access: articles freely available online

- High visibility within the field

- Retaining the copyright to your article

Submit your next manuscript at $>$ springeropen.com 